\title{
The SBPT and conflicts of interest
}

Data from studies conducted in the United States have shown that, in the year 2000, the drug industry financed more than 314,000 events for doctors, from dinners to weekends in exotic locales, at a cost of almost two billion dollars. This raises the issue of conflict of interest (COI).

The term COl encompasses favorable or unfavorable attitudes (toward certain techniques, medications, or devices) that can be influenced by potential financial gain. Such COls are most commonly mentioned in reference to conferences, at which a physician, who has received financial incentives, endorses a pharmaceutical product in a subtle (or not so subtle) way. The New England Journal of Medicine, the most prestigious medicine journal, has recently changed its editorial policy of not inviting authors presenting potential COls to write review articles or editorials regarding treatment of common diseases, asserting that there are no authors that do not have some type of COl. Many studies show that financial COls can affect the judgment of medical professionals and researchers. In a systematic review, it was concluded that "the financial relationships among the industry, scientific investigators and academic institutions are generalized and the [COls] derived from these ties might influence biomedical research in a significant way". An editorial by Angell, published in 2000, had the provocative title of "ls academic medicine for sale?".

In the medical field, clinical and research practice is profoundly influenced by large clinical trials, by the development of guidelines and consensuses and by the continuing medical education movement, which has recently included the development of corporate sponsored websites. Powerful scientific and socioeconomic forces have influenced these three areas. Medical advances require carefully controlled clinical trials with large numbers of patients, scientists and physicians. This process involves considerable financial investment and great effort on the part of the investigators. Some funding comes from research grants, but the major part comes from industry sources. Conducting objective research, while maintaining scientific honesty and ethics separate from the influence of financial considerations, is a great challenge.

The first randomized clinical trial conducted in the field of medicine was carried out in 1948 by phthisiologists who showed that streptomycin could cure tuberculosis. Clinical trials rapidly became more numerous and, in recent years, a new specialist title, that of "clinical investigator", was created. Clinical investigators are funded by the pharmaceutical industry and take part, almost anonymously, in large, often global, clinical trials.
With the expansion of these trials to developing countries, the so-called opinion leaders, generally connected to impoverished public universities, have had a new source of personal and institutional income, as well as a guarantee of a certain notoriety, from their participation in these studies, receiving lecturer grants and administrative positions in professional societies to which they belong, as well as being invited to give classes and seminars at regional and national conferences. As medical professionals, we have to ensure that altruism, and not outside interests, will be our primary motivation.

Without the support of medical societies, which obviously include the Sociedade Brasileira de Pneumologia e Tisiologia (SBPT, Brazilian Society of Pulmonology and Phthisiology), we could organize neither large conferences with various foreign guests (some of them with potential COls) nor continuing education courses. Minus such support, we would also be unable to implement lnternet educational platforms, as we have been doing. The SBPT and the industry representatives with whom we have had contact clearly understand the limits of this partnership. Industry representatives have never tried to improperly influence the content of the SBPT instructional programs. It is essential that this transparency be extended to other fields. The strategy is to obligate clinical investigators to make open declarations, either in writing or orally at the opening of lectures and conferences, of any potential COl. In addition, clinical investigators should be require to publish scientific reports to accompany the publication of research (who controls the data in the study?), including the guidelines established by the SBPT and according to the regulations issued by the Conselho Federal de Medicina (CFM, Federal Medical Council). From this declaration, the audience or the reader can judge potential biases. Obviously, the declaration of a potential COl should not be construed as synonymous with dishonesty.

We should discuss whether colleagues who have risen to administrative positions in the SBPT should be allowed to maintain specific ties to certain pharmaceutical companies (i.e., be subjected to the same scrutiny as editors of large medical publications). Colleagues and the public at large must understand that industry support is vital for the advancement and dissemination of medical knowledge. However, the time is ripe for discussing to exactly what extent this progress and its expansion are imbued with ulterior motives.

Carlos AC Pereira

President of the SBPT 